\title{
HIGH PERFORMANCE LIQUID CHROMATOGRAPHIC ASSAY OF NEOTHRAMYCIN IN BIOLOGICAL FLUIDS
}

\author{
TAKEShI Kusama and AKIRA OKada \\ Pharmaceutical Development Laboratories, Meiji Seika Kaisha, Ltd., \\ 580 Horikawa-cho, Saiwai-ku, Kawasaki, Japan \\ Masaji Sezaki \\ Central Research Laboratories, Meiji Seika Kaisha, Ltd., \\ 760 Morooka-cho, Kohoku-ku, Yokohama, Japan \\ (Received for publication March 11, 1981)
}

\begin{abstract}
A high performance liquid chromatographic method for quantitative determination of neothramycin in plasma was developed. The procedure involves pretreatments for the removal of endogenous materials in plasma samples and separation on a reversed phase column. The antibiotic was monitored with a fluorescence detector and confirmed by a specific sulfite adduct shift of retention time. A linear response for serum samples containing neothramycin ranging from 50 to $500 \mathrm{ng} / \mathrm{ml}$ was obtained. The sensitivity of this method was sufficient to measure neothramycin in human plasma for 120 minutes after a $24 \mathrm{mg} / \mathrm{m}^{2}$ (body surface area) intravenous injection.
\end{abstract}

Neothramycin, found by UMEZAWA and coworkers ${ }^{1,2)}$, is a new member of the pyrrolo(1,4)benzodiazepine group of antibiotics including anthramycin ${ }^{3)}$, tomaymycin ${ }^{4)}$ and sibiromycin ${ }^{5)}$. These antibiotics have broad antitumor spectrum against various transplanted tumors in animals. The acute toxicity of neothramycin in mice was lower than that of other antibiotics of this group, and no cardiotoxicity or neurotoxicity was observed in hamsters. There is also no bone marrow toxicity ${ }^{6)}$, therefore, some clinical application is expected.

We investigated the quantitative microassay to determine the dosage regimen and to study the tissue distribution of neothramycin. Since neothramycin has weak activity against most bacteria $(>50 \mathrm{mcg} / \mathrm{ml})^{1)}$, bioassay was not suitable for microdetermination. GC-MS analysis also did not give good recovery and reproducibility due to the limited stability of this antibiotic. On the other hand, a high performance liquid chromatographic method (HPLC) on reversed phase column gave good separation and reproducibility. Moreover, when a fluorescence detector was used, high sensitivity could be obtained because neothramycin originally has a strong fluorescence.

In this paper, we wish to report on the HPLC monitoring with a flow fluorescence detector for the quantitative analysis of neothramycin in plasma.

\section{Experimental}

Chemicals and Reagents

Neothramycin (an equilibrium mixture of neothramycins A and B) ${ }^{1)}$ was prepared from the cultured broth of Streptomyces No. MC916-C4 on an industrial scale, in our laboratory. 3-O-Methylneothramycin A was crystallized by the method of TAKEUCHI et al. ${ }^{1)}$ Methanol, acetone and acetonitrile were of liquid chromatographic grade from Wako Pure Chemical Co., Japan. Sodium hydrogen sulfite was reagent grade from Junsei Chemical Co., Japan. Sep-pak $\mathrm{C}_{18}$ was from Waters Assoc., 
U.S.A. Deionized and distilled water was used for mobile phase and sample preparation. Human plasma of a cancer patient injected with neothramycin was kindly supplied by Dr. NAKAJIMA, Japan National Medical Center Hospital. Healthy human plasma was obtained from a volunteer.

\section{Apparatus}

The liquid chromatography system consists of a Waters Association Model 6000-A pump with a U6K injector, Data module 730 recorder and a Hitachi 650-10 liquid chromatographic fluorometer (excitation at $310 \mathrm{~nm}$, emission at $420 \mathrm{~nm})$. Analysis was performed by using a column $(30 \mathrm{~cm} \times 4 \mathrm{~mm}$ ID) with a precolumn $(5 \mathrm{~cm} \times 4 \mathrm{~mm}$ ID), both packed with LS-410 octadecyl silica phase-bonded silica gel (5 $\mu \mathrm{m}$, Toyo Soda Manufacturing Co., Japan).

\section{Chromatographic Conditions}

The solvent used for mobile phase was a mixture of methanol and distilled water $(29: 71 \mathrm{v} / \mathrm{v})$ which was degassed by sonication before use. The operating conditions were as follows: flow rate, $1.0 \mathrm{ml} /$ minute; pressure, about $3000 \mathrm{psi}$; column temperature, $30 \sim 33^{\circ} \mathrm{C}$; fluorescence sensitivity, $\mathrm{PM}$ gain normal and range 10 (slit width; excitation $10 \mathrm{~nm}$, emission $10 \mathrm{~nm}$ ).

Standard and Internal Standard Solutions

For a satisfactory quantitative analysis, 3-O-methylneothramycin $\mathrm{A}$ was used as the internal standard because its physicochemical properties are very similar to neothramycin and it has a different retention time. Stock solutions containing $10 \mu \mathrm{g}$ of neothramycin and $10 \mu \mathrm{g}$ of $3-O$-methylneothramycin $\mathrm{A}$ per $\mathrm{ml}$ in water were prepared as the standard and internal standard, respectively, and stored at $-20^{\circ} \mathrm{C}$ during an experimental period. Concentrations of neothramycin were adjusted at four levels $(50,100,200$ and $500 \mathrm{ng} / \mathrm{ml})$ by diluting the stock solution with water. The internal standard solution of $100 \mathrm{ng} / \mathrm{ml}$ was also prepared in the same way.

\section{Extraction Procedure}

The extraction procedure is shown in Fig. 1. The extraction was carried out in $10 \mathrm{~cm}$ by 10 mm ID test tubes which were siliconated before use to prevent adhesion of this antibiotic to the glass surface. Standard solutions were used instead of saline for making a calibration curve, and determining the reproducibility and recovery.

\section{Results and Discussion}

Typical chromatograms of neothramycin from a standard sample solution and patient plasma sample are shown in Fig. 2-(A), (B) and (C). Neothramycins $\mathrm{A}, \mathrm{B}$ and 3-O-methylneothramycin A were eluted with retention times of 8.2, 13.2 and 21.7 minutes, respectively. Although neothramycins $\mathrm{A}$ and $\mathrm{B}$ are inter-
Fig. 1. An extraction procedure of neothramycin from plasma samples.

Plasma $0.3 \mathrm{ml}$

1. added 3-O-methylneothramycin A solution $100 \mathrm{ng} / \mathrm{ml}(0.3 \mathrm{ml})$.

2. added saline $(0.3 \mathrm{ml})$.

3. precipitated with acetone $(2.7 \mathrm{ml})$.

4. centrifuged at $3000 \mathrm{rpm}$ for 20 minutes.

Supernatant about $3.0 \mathrm{ml}$ ppt. ... (discarded)
1. evaporated to dryness.
2. dissolved with water $(2.0 \mathrm{ml})$.
3. adsorbed on a Sep-pak $\mathrm{C}_{18}$ (Waters Associa-
tion) column $(10 \mathrm{~mm} \times 10 \mathrm{~mm}$ ID)
4. washed with water $(3.0 \mathrm{ml})$.
5. eluted with acetonitrile $(3.0 \mathrm{ml})$.
6. evaporated to dryness
Residue
1. dissolved with water $(300 \mu 1)$.
2. injected $20 \mu 1$ to HPLC column.
HPLC analysis
convertible in an aqueous solution ${ }^{1,2)}$, they are clearly separated at almost $1: 1$ by this analysis. The endogenous materials in plasma samples did not interfere with this assay and good separation was obtained as shown in Fig. 2-(C).

Standard solutions for a calibration curve were prepared by extraction in the same way from blank plasma samples to which were added different concentrations of neothramycin $(50 \sim 500 \mathrm{ng} / \mathrm{ml})$. As shown in Fig. 3, a good linear relationship was observed between the peak height ratio (neothramycin $\mathrm{A}+\mathrm{B} / 3-\mathrm{O}$-methylneothramycin $\mathrm{A}$ ) and the drug concentrations in the range studied. A linear least- 
Fig. 2. Chromatograms of neothramycin.

(A) A standard solution (NTM* $100 \mathrm{ng} / \mathrm{ml}, \mathrm{MNTM}^{* *} 100 \mathrm{ng} / \mathrm{ml}$ ), (B) a sample from a plasma blank with 3-O-methylneothramycin A, (C) from a plasma of a patient with kidney cancer sampled at 60 minutes after a 55-minute constant intravenous infusion of $36 \mathrm{mg}$ of neothramycin per $\mathrm{m}^{2}$ and (D) a sample added $\mathrm{NaHSO}_{3}$ to the (C).

* NTM = Neothramycin, $\quad * * \mathrm{MNTM}=3-O$-methylneothramycin A

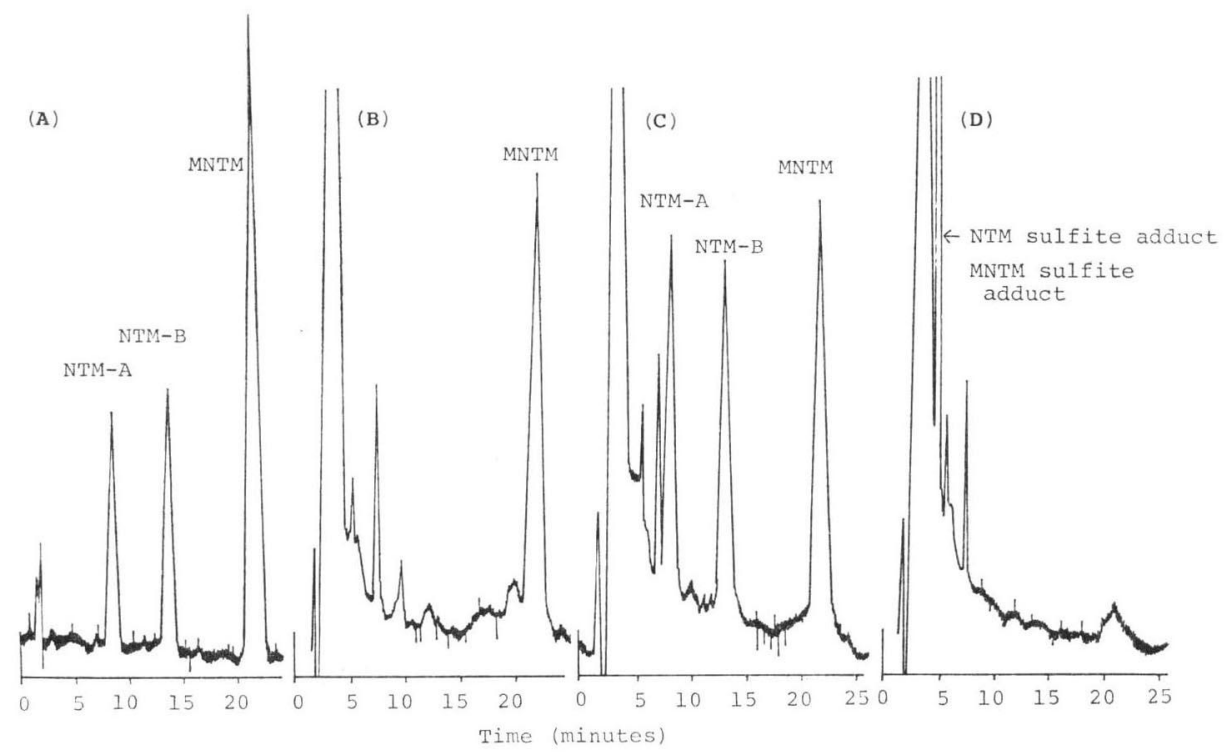

Fig. 3. Calibration curve of neothramycin in plasma.

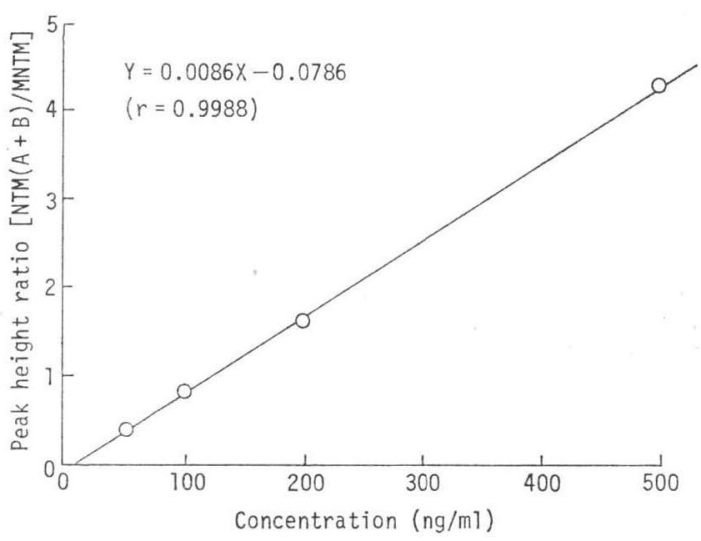

Table 1. Recovery of neothramycin from human plasma samples.

\begin{tabular}{c|c|c}
\multicolumn{2}{c}{} & \multicolumn{1}{c}{$(\mathrm{n}=5)$} \\
\hline $\begin{array}{c}\text { Amount of } \\
(\mathrm{ng} / \mathrm{ml})\end{array}$ & $\begin{array}{c}\text { Recovery } \\
(\%)\end{array}$ & $\begin{array}{c}\text { Coefficient } \\
\text { variation } \\
(\%)\end{array}$ \\
\hline 50 & 82.8 & 4.07 \\
100 & 85.7 & 3.22 \\
200 & 88.7 & 1.72 \\
500 & 89.0 & 2.01
\end{tabular}

Recovery of MNTM $(100 \mathrm{ng} / \mathrm{ml})$.

$76.6 \% \mathrm{CV}=3.79 \%(\mathrm{n}=20)$.

squares regression analysis gave a coeffecient of correlation ( $r$ ) of 0.9988. All data could be obtained with only $0.3 \mathrm{ml}$ of plasma samples. The detection limit of this procedure is about $20 \mathrm{ng} / \mathrm{ml}$.

The recovery of neothramycin added to plasma was determined by comparing the peak heights from plasma samples containing 50 500 $\mathrm{ng}$ of this drug per $\mathrm{ml}$ with those obtained from aqueous standards of the same concentration. These results (Table 1) indicated that the recovery was greater than $80 \%$ and peak heights were fairly reproducible.

We had already found that, in an aqueous solution, neothramycin reacts with sulfite ion and forms a stable sulfite adduct ${ }^{7}$ having a different retention time on the chromatogram (Fig. 4). A. 
Fig. 4. Structures of neothramycins (A), their hydrated forms in water $(\mathrm{B})^{2)}$ and their sodium sulfite adducts (C). ${ }^{7)}$

\begin{tabular}{l|ll}
\hline & \multicolumn{1}{|c}{$\mathrm{R}_{1}$} & $\mathrm{R}_{2}$ \\
\hline Neothramycin A & $\mathrm{OH}$ & $\mathrm{H}$ \\
Neothramycin B & $\mathrm{H}$ & $\mathrm{OH}$ \\
3-O-Methylneothramycin A & $\mathrm{OCH}_{3}$ & $\mathrm{H}$ \\
\hline
\end{tabular}<smiles>[R]C1([R2])CC[C@H]2C=Nc3cc(O)c(OC)cc3C(=O)N21</smiles>

(A)

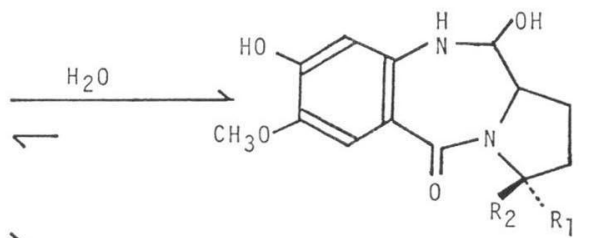

(B)

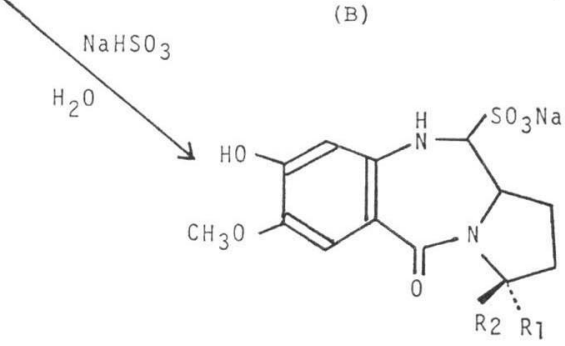

(C)

Fig. 5. Concentration profile of neothramycin in plasma of a patient with malignant lymphoma after constant intravenous infusion. (Dose: $24 \mathrm{mg} / \mathrm{m}^{2}$ )

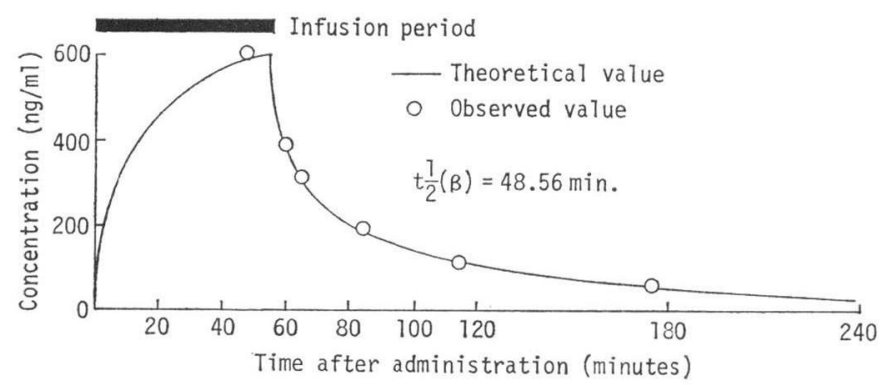

small amount of sodium hydrogen sulfite was added to the sample solution, the mixture was blended for a few seconds and then injected into a HPLC column. The peaks of neothramycin disappeared and a new adduct peak appeared at 6.1 minutes of retention time [Fig. 2-(D)]. The peaks of neothramycin could be identified immediately by this shift.

Some plasma and serum samples from patients on this antibiotic were analyzed by this procedure. Fig. 5 shows the computer-fitted curve using a two-compartment model for neothramycin concentration in plasma of a patient with malignant lymphoma following a intravenous administration of $24 \mathrm{mg} / \mathrm{m}^{2}$. The half life $(\mathrm{t}(1 / 2) \beta)$ of this antibiotic was 48.56 minutes in this case. The sensitivity of this method was sufficient to measure neothramycin in plasma for 120 minutes after intravenous administration. It was proved that this neothramycin assay employing HPLC is feasible for routine clinical use. 


\section{Acknowledgments}

The authers wish to express their sincere thanks to Prof. Hamao Umezawa, Dr. Tomio Takeuchi and Dr. Shinichi Kondo, Institute of Microbial Chemistry, and Prof. Hiroshi Fujita, Tsurumi University for their guidance and encouragement. We also thanks to Dr. Osamu NaKaJima, Japan National Medical Center Hospital for providing patient plasma samples.

\section{References}

1) Takeuchi, T.; M. Miyamoto, M. Ishizuka, H. Naganawa, S. Kondo, M. Hamada \& H. Umezawa: Neothramycins A and B, new antitumor antibiotics. J. Antibiotics 29: 93 96, 1976

2) Miyamoto, M.; S. Kondo, H. Naganawa, K. Maeda, M. Ohno \& H. Umezawa: Structure and synthesis of neothramycin. J. Antibiotics 30: 340 343, 1977

3) Leimgruber, W.; V. Stefanovic, F. Schenker, A. Karr \& J. Berger: Isolation and characterization of anthramycin, a new antitumor antibiotic. J. Amer. Chem. Soc. 87: 5791 5793, 1965

4) Arima, K.; M. Kohsaka, G. Tamura, J. Imanaka \& H. Sakai: Studies on tomaymycin, a new antibiotic. I. Isolation and properties of tomaymycin. J. Antibiotics 25: 437 444, 1972

5) Brazhnikova, M. G.; N. V. Konstantinova \& A. S. Mesentsev: Sibiromycin: Isolation and characterization. J. Antibiotics 25: 668 673, 1972

6) Hisamatsu, T.; S. Uchida, T. Takeuchi, M. Ishizuka \& H. Umezawa: Antitumor effect of a new antibiotic, neothramycin. Gann 71:308 312, 1980

7) Umezawa, H.; T. Takeuchi, T. Hisamatsu, M. Sezaki \& Y. Kowaze: Neothramycin sodium sulfite adducts. Japan Patent Kokai 80-69,587, 1980 